\title{
Synoptic History of Microbiology and Microbial Quantumics
}

\author{
Aigbogun Ighodaro Edwin ${ }^{1, ~ *, ~ E m m a n u e l ~ M a t h e w ~}{ }^{1}$, Abubakar Idris ${ }^{2}$ \\ ${ }^{1}$ Department of Microbiology, Faculty of Science, Kaduna State University, Kaduna, Nigeria \\ ${ }^{2}$ Microbiology Unit, Department of Biological Science, Niger State Polytechnic, Zungeru, Nigeria \\ Email address: \\ aigbogunighodaro@gmail.com (A. I. Edwin),emmanuelmathew700@gmail.com (E. Mathew), eedreez98@gmail.com (A. Idris) \\ ${ }^{*}$ Corresponding author
}

\section{To cite this article:}

Aigbogun Ighodaro Edwin, Emmanuel Mathew, Abubakar Idris. Synoptic History of Microbiology and Microbial Quantumics. Advances in Bioscience and Bioengineering. Vol. 6, No. 3, 2018, pp. 30-33. doi: 10.11648/j.abb.20180603.11

Received: September 18, 2018; Accepted: October 24, 2018; Published: December 24, 2018

\begin{abstract}
Microbiology is defined as the study of living organism that are not visible to the naked eyes. Microbiology as a discipline has evolved via research and discoveries over centuries and decades. Its definitions and prospects have changed and its paradigm has enlarged in terms of meaning, research and understanding. These researches have implanted milestones in the race of man. This review paper is set to discuss some synoptic historical events in Microbiology. From the events in the Garden of Eden to the discovery of the first animacules, through spontaneous generation disputations and fermentation era, discovery of antibiotics to present events in biotechnology, nanotechnology, and future branch of microbiology which is microbial quantumics. Microbial quantumics' is defined as the study of behavioral pattern of microbes in the subatomic realm. The possibility of studying the behaviour of microbes in the subatomic realm is unspoken because of difficulties and uncertainty of man to tap into that 'yet-to-be-born' era. One of the difficulties that veils man's eyes is setting up an experimental design or model to really see the anomalous comportement of the animacules for ourselves. The spinning of microbes at a given rotation per minute and in a carefully designed model can twitch history to discovering more quantumics by microbes. Although the behavioral phenomenon by the animacules may be asymptotic but can be detected if there is change in final state $\mathrm{W}^{(\mathrm{f})}$ and the initial state $\mathrm{W}^{(\mathrm{i})}$ in the experimental design. Therefore, microorganisms will take the lead way to understanding the subatomic realm.
\end{abstract}

Keywords: History, Microbiology, Microbial Quantumics

\section{Introduction}

Microbiology as a discipline actually began from the Garden of Eden. God created man and every living thing therein [1]. But man hasn't constructed the tools for the study of these tiny creatures until Robert Hooke diagrammatically described a mould (fungus) in 1665. However, the first bacteria was first viewed by a Dutch Merchant; Anthony Van Leeuwenhook in 1674. He wrote to the Royal Academy of Science "very many tiny animalcules, wherefore some were roundish, others were a bit oval. On these last, I saw two little legs near the head, and two little fins at the hind most end of the body. Others were some what longer than an oval, and these were very slow a moving, and few in number. These animacules had diverse colour, some being whitish and transparent; others with green and very glittering with scales, others gain were green in the middle, and before and behind white; others were ashed grey. And the motion of most of these animacules in the water was so swift, and so various, upwards, downwards, and round about, that twas wonderful to see" [2].

Ever since Leuwenhook's discovery, there was claim that the existences of these animalcules were real, then scientists went head long to solve world's misery through the noble discipline and to prove the existence of these animacules. These scientists turned the knob of history to give the world a meaning via research and discoveries and ensignia the phase or ages of man. One of such time in the $18^{\text {th }}$ century was on 
spontaneous generation.

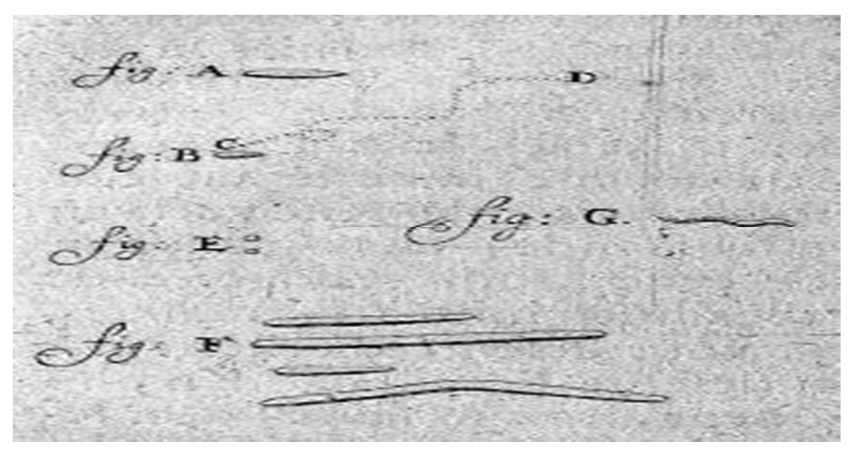

Figure 1. Van Leewenhook Drawing.

\section{Spontaneous Generation}

This conviction held that life could and regularly did originate from non-living matter. The theory of spontaneous generation was commonly accepted from the earliest periods of biological history until the middle of the last century [3]. The work of the L. Pasteur and F. Redi was highly significant in representing that spontaneous generation does not normally take place today. However, evolutionists often assumed that some form of spontaneous generation occurred in the far distant past, even though they consider that it is unlikely that it could occur today. This discovery led to further unwinding in the field of fermentation [2].

\subsection{Fermentation Discovery}

Pasteur demonstrated that fermentation is caused by the growth of microorganisms, and the emergent growth of bacteria in nutrient broths is not due to spontaneous, but rather to biogenesis [4]. A local wine manufacturer, M. Bigot, the father of his student, sought for his advice on the problems of making beetroot alcohol and ferment after long storage. In 1857, he developed his ideas stating that: "I intend to establish that, just as there is an alcoholic ferment, the yeast of beer, which is omnipresent decomposed sugar into alcohol and carbonic acid, so also there is a particular ferment, lactic yeast always present when sugar became lactic acids. From his son-in-law perspective, Pasteur presented his experiment on sour milk titled "Latate Fermentation" in August 1857 [5].

$\mathrm{He}$ established that yeast was conscientious for fermentation to produce alcohol from sugar, in the absent of oxygen. He also verified that fermentation could also produce lactic acid (due to bacterial contamination), which makes wines sour. This is regarded as the foundation of Pasteur's fermentation experiment and contradicts of spontaneous generation of life. Pasteur's research also showed that the growth of micro-organism was responsible for spoiling beverages, such as beer, wine and milk. With this established, he invented a process in which liquids such as milk were heated to a temperature between 60 and $100^{\circ} \mathrm{C}$. Research continued not just in the food industries but in infectious diseases and medicine by Koch and Ehrlich.

\subsection{Koch Postulates}

Robert Koch was named the father of Clinical Microbiology and Bacteriology because of his postulates on infectious disease and culture of bacteria. He worked on Anthrax and in 1877, where he revealed typical Bacilli (Bacillus anthracis) with squarish ends in the blood of cattle that died from the disease. Other bacteria discovered by Robert Koch are Mycobacterium tuberculosis the causative agent of tuberculosis (1882), Vibrio cholera which causes cholera (1883) [6].

He developed a technique for isolating bacteria on a culture plate. Robert Koch was the first person to grow bacteria on solid culture media, where he employed gelatin as a solidifying agent. [7]. In 1905, he was awarded the Nobel Prize for Physiology and Medicine, for investigations and discoveries of the disease tuberculosis "TB". Koch's postulate provided guidelines to identify the causative agent of an infectious disease though they were some adjustments $[6,8]$.

Koch's postulates are:

(1) A specific organism can always be found in association with a given disease, according to him infectious agent must before the disease come into play.

(2) The organism can be isolated and grown in pure culture in the laboratory that is, this causative agent can be obtained if cultured.

(3) The pure culture will produce the disease when inoculated into a susceptible animal. He also found out that when the causative agent is inoculated into a healthy laboratory animal the same disease would manifest.

(4) It is possible to recover the organism in pure culture from the experimentally infected animal or diseased animal [2].

\subsection{Discovery of Antibiotics}

In 1908 to 1910, Paul Ehrlich during his chose selective stains; synthesized arsenic multifarious arsphenamine and test them against some organism and he found out that were inhibiting the growth of those microorganism. Because of the effectiveness of this compound against $T$. pallidum, the compound was coined magic bullet. His discovery led to the existence antibiotics for the treatment of microbial infections [9].

\subsection{Biotechnology}

Biotechnology is the integrated use of biochemistry, microbiology, and engineering sciences in order to achieve technological (industrial) application of the capabilities of micro-organisms, cultured tissue cells. The name biotechnology was given by an Hungarian engineer Karoly Ereky in 1919 to describe a technology based on converting raw materials into a more useful product [10]. After World War II, crucial discoveries were brought to light. In 1953, Watson and Crick cleared the mysteries of DNA as a genetic material, by giving a structural model of DNA [11] while in 
2003, the human genome project was completed. The field of biotechnology has evolved into genetic engineering, proteomics, plant biotechnology even cloning [12].

\subsection{Nanotechnology}

This is the talk of the world at present. Nanotechnology is the design and application of materials of $10^{-9}$ scale $[13,14]$. Nanoscopic materials has long existed but was not discovered until Norio Tanichishi and Richard Feyman opened the door to this reality as are today called the fathers of nanotechnology. The application of this field has span through medical, environment, food and industrial sector around the globe. Its' use is still ever increasing as its risks are known. At present there are nano meds, nano foods made from natural or synthetic nano materials into an unphantomable form that can be consumed and accepted by the living cells. The risks of this evolving technology is still ascertain in many countries especially in the developing countries though it is the field of the moment [14].

\subsection{Microbial Quantumics}

Microbial quantumics is one of the futuristic step that will enable scientist understand the quantum real. Microbial quantumics as the behaviour of microbes in the sub atomic realm. Microbes are the only living organism that really experiences this realm. However, because of some uncertainty the research might still be in the cocoon. One of such difficulty is to create a pilot scale for the visualization of the behaviour of microbes in the realm.

Its' still of possibility to create pilot scale experimental study with photosynthetic microbe to observe their behaviour. It doesn't have to be metal or the more the intensity of light ray unto the microbe as stated by Albert Einstein [15]. The pure stationary system that we have studied hitherto must be subject to non- stationary interactions in set ups of realistic experiments which allows preparation and detection' [16].

For example, the colour of the sun is violet but what we see as the colour of the sun isn't most of the time violet. Because of the circumstances such as distance, rotation and revolution that surrounds the globe, which cause light wave to bend [17].

Another example on Light wave is its ability to travel and bend. When light ray strikes water, it bends in water (refraction). Outside the water surface, the light ray as wave is straight, but when it strikes the surface of the water, it bends $[17,18]$ but what if the aquatic body like the fishes see something else? However, they react and live accordingly displaying manner of behaviour to dodge the ray. Light isn't the only classical example, radio wave and laser beams can be used as source too.

In the microbial world, reactions happen when we can glitch a microbe in light or wave, they could react and display manner of behaviour or mannerism as a way of expression in the other dimension. In some cases, it may be asymptotic but we can detect it overtime as long as there is a difference between the final state, $\mathrm{W}^{(\mathrm{f})}$ and the initial state $\mathrm{W}^{(\mathrm{i})}[19]$.

\section{Conclusion and Recommendation}

Microbial quantumics is a possibility to solve greatest miseries in the world as it will birth answers to understanding humanity and the world we occupy. In the nearest future, the definition of microbiology will metamorphose from the study of living things too small to be seen except with the aid of microscope, to the study, design and lifestyle/behaviour of tiny animalcules to solve world's misery and for economic gain.

\section{References}

[1] The Holy Bible. (2011). Genesis 1. Evangel Publisher Limited, pp 1-2.

[2] Nester, A., Roberts, P., Pearsall, N. N. and Anderson, D. G. (2009). Microbiology: A Human Perspective, eight edition, Mc Graw Hill Education, pp 1.

[3] Jerry, B. (1993). A brief history of the theory of spontaneous generation. CEN Technology Journal volume 7(1), pp. 73-81.

[4] Chaudhari, P., Shetty, A. and Soman, R. (2015). The Concepts that Revolutionized the Field of Infectious Diseases. The Journal of the Association of Physicians of India, 63(8), 9092.

[5] Manchester, K. L. (2007). Louis Pasteur, fermentation, and a rival. South African Journal of Science, 103(9-10), 377-380.

[6] Blevins, S. M. and Bronze, M. S. (2010). Robert Koch and the 'golden age' of bacteriology. International Journal of Infectious Diseases, 14(9), e744-e751.

[7] Atlas, R. M. (2005). Handbook of media for environmental microbiology. CRC press.

[8] Zetterström, R. (2006). Robert Koch (1843-1910): Investigations and discoveries in relation to tuberculosis. Acta Paediatrica, 95(5), 514-516.

[9] Bosch, F. and Rosich, L. (2008). The contributions of Paul Ehrlich to pharmacology: a tribute on the occasion of the centenary of his Nobel Prize. Pharmacology, 82(3), 171-179.

[10] Prasad, B. D., Sahni, S., Kumar, P. and Siddiqui, M. W. (Eds.). (2017). Plant Biotechnology, Volume 1: Principles, Techniques, and Applications. CRC Press.

[11] Watson, J. D. and Berry, A. (2009). DNA: The secret of life. Knopf.

[12] Fernie, A. R., Trethewey, R. N., Krotzky, A. J. and Willmitzer, L. (2004). Metabolite profiling: from diagnostics to systems biology. Nature reviews molecular cell biology, 5(9), 763.

[13] Suresh, N. and Digvir, S. J. (2011). Nanotechnology for the food and bioprocessing industries. Food Bioprocess Technology, 4:39-47.

[14] Aigbogun, I. E, Mohammed, S. S. D. and Orukotan, A. A (2018). The role of Nanotechnology. Lambert Academic Publishing, Pp 5-9. 
[15] Arons, A. B. and Peppard, M. B. (1965). Einstein's Proposal of the Photon Concept - a Translation of the Annalen der Physik Paper of 1905. American Journal of Physics, 33(5), 367-374.

[16] Florain, S. (2009). Quantum Physics. Springer, pp 123, 196197.

[17] Yu, N., Genevet, P., Kats, M. A., Aieta, F., Tetienne, J. P., Capasso, F. and Gaburro, Z. (2011). Light propagation with phase discontinuities: generalized laws of reflection and refraction. Science, 1210713.

[18] Borcherds, P. (2002). Newton to Einstein the trail of light: an excursion to the wave-particle duality and the special theory of relativity. European Journal of Physics, 23(2), 233-234.

[19] Hawking, S. W. (1975). Particle creation by black holes. Communications in mathematical physics, 43(3), 199-220. 